\title{
Investigating the effect of colloids on the performance of a biofilm membrane reactor (BF-MBR) for treatment of municipal wastewater
}

\author{
T Leiknes*, I lvanovic and H Ødegaard \\ NTNU - Norwegian University of Science and Technology, Department of Hydraulic and Environmental Engineering, \\ S.P. Andersensvei 5, N-7491 Trondheim, Norway
}

\begin{abstract}
Performance of membrane reactor in combination with moving-bed-biofilm reactor (BF-MBR) for treatment of municipal wastewater was investigated in relation to different organic loading rates; high and low rates. The membrane was operated with a constant flux of $50 \mathrm{LMH}$ and $96 \%$ recovery. The fouling rate was evaluated as development of the trans-membrane pressure (TMP) during the operational time. Suspended solids (SS) concentrations, organic matter (COD/FCOD), particle size distributions (PSD), capillary suction time (CST) and time to filter (TTF) were measured daily and further related to TMP in order to determine major fouling factors. A higher fouling potential was observed for high-rate operating conditions. A fraction of organic matter below $1.2 \mu \mathrm{m}$ was mostly related to changes in TMP. Furthermore, a higher amount of particulate fraction below $0.1 \mu \mathrm{m}$ in membrane reactors during high-rate operating conditions presented a dominant contribution to membrane fouling and colloidal fouling.
\end{abstract}

Keywords: biofilm membrane reactor, colloidal fouling, particle size distribution, fractional COD distribution

\section{Introduction}

Membrane bioreactors (MBR) combine the biological treatment processes with membrane filtration to provide an advanced level of organic and SS removal. The process is a refinement of the conventional activated sludge (AS) process where membranes primarily serve to replace the clarifier. The current and most commonly used MBR reactor design employed in municipal wastewater treatment is the submerged process configuration where the membrane modules are immersed in an aerated biological reactor (AS-MBR). An alternative treatment scheme to the AS-MBR is combining a biofilm reactor with membrane filtration for enhanced biomass separation (BF-MBR) (Leiknes et al., 2005; Åhl et al., 2005; Melin et al., 2005). Biofilm processes are also used in wastewater treatment and several reactor designs can be applied, i.e. trickling filters, rotating biological contactors, fluidised bed reactors etc. The moving bed biofilm reactor (MBBR) is an alternative biofilm reactor supplied by AnoxKaldnes (Norway). The MBBR process consists of small plastic biofilm carriers used to create a very large surface area for the biofilm to grow on and are suspended in the reactor by aeration (Ødegaard et al., 1994). Compared to other biofilm reactors the MBBR tolerates high particulate and organic loading rates and is not susceptible to clogging by particulates (Ødegaard et al., 2000). The process is also very compact compared to conventional AS processes. A critical and inherent feature in any membrane process is fouling of the membrane. Understanding and controlling membrane fouling will therefore be a central issue in developing either of the systems. Fouling is caused by different

This paper was originally presented at the 2006 Water Institute of South Africa (WISA) Biennial Conference, Durban, South Africa, 21-25 May 2006

* To whom all correspondence should be addressed.

뚕 +47 7359 4758; fax: +47 7359 1298; e-mail: torove.leiknes@ntnu.no substances (i.e. solids, particles, dissolved constituents) and the mechanisms are rather complex and interrelated. The SS concentrations in the effluent from an MBBR reactor are typically below $200 \mathrm{mg} / \ell$ depending on site wastewater characteristics and loading rates and the SS to be removed from the effluent are therefore relatively low. This aspect of the process is beneficial when considering the combination of the biofilm reactor with membrane separation of the biomass. Given that the high MLSS concentrations commonly used in AS-MBR processes present a fouling issue, one would expect that a benefit of the BF-MBR would be to reduce membrane fouling as operation with low SS loading is possible. Coupling a compact biofilm process with efficient particle separation potentially provides a stable highquality effluent with the possibility for better fouling control based on lower SS in the membrane reactor.

Membrane fouling manifests in various ways and certain types of fouling (reversible) can be removed by backwashing, i.e. cake formation and loose deposits, while others are permanent (irreversible), fouling which is only recoverable by chemical cleaning (Leiknes et al., 2005). A key factor to MBR development is fouling minimisation and control. A lot of effort and research has been done to gain more knowledge of the phenomenon in the past 10 to 15 years. A literature review shows that the number of references sorted out with the keywords: fouling and membrane and (particle or suspension or dispersion) raised from less then 5 in the early 1990s to around 40 per year in 2004 (Aimar, 2003). Suspended solids are very often identified as a main foulant (Defrance et al., 2000; Bae et al., 2005) where the significance of the submicron colloidal fraction in the SS has been reported to correlate with membrane fouling rates (Wisniewski et al., 2000; Li et al., 2005; Rosenberger et al., 2006). In MBR processes fouling has also been attributed to extracellular polymeric substances (EPS) and soluble microbial products (SMP) (Nagaoka et al., 1996; Chang et al., 2002; Li et al., 2005; Rosenberger et al., 2006).

The objective of this study was to investigate the effect of 


\begin{tabular}{|c|c|}
\hline \multicolumn{2}{|c|}{$\begin{array}{c}\text { TABLE } 1 \\
\text { Operating conditions for MBBR and for membrane reactor }\end{array}$} \\
\hline \multicolumn{2}{|l|}{ Moving-bed-biofilm reactor } \\
\hline $\begin{array}{l}\text { Number of reactors (in series): } 4, \\
\text { Type of carrier: K1 - AnoxKaldnes, } \\
\text { Surface area for biofilm growth }-325 \mathrm{~m}^{2} /\left(\mathrm{m}^{3} \text { reactor volume }\right)\end{array}$ & $\begin{array}{l}\text { Volume of each reactor: } 65 \ell \\
\text { Filling fraction }-67 \% \text { of reactor volume } \\
\text { Total growth area }-84.5 \mathrm{~m}^{2}\end{array}$ \\
\hline \multicolumn{2}{|l|}{ Operating characteristics - loading rates } \\
\hline High rate operation & Low rate operation \\
\hline $\begin{array}{l}\text { 1h hydraulic retention time (HRT) } \\
\text { Average load: } \\
\mathrm{COD}-47 \mathrm{gO}_{2} / \mathrm{m}^{2} \cdot \mathrm{d} \\
\text { FCOD } 1.2-23 \mathrm{gO}_{2} / \mathrm{m}^{2} \cdot \mathrm{d}-\mathrm{GF} / \mathrm{C} 1.2 \mu \mathrm{m} \\
\text { FCOD } 0.45-18 \mathrm{gO}_{2} / \mathrm{m}^{2} \cdot \mathrm{d} \mathrm{GF} / \mathrm{C} 0.45 \mu \mathrm{m} \\
\text { FCOD- } 0.1-13 \mathrm{gO}_{2} / \mathrm{m}^{2} \cdot \mathrm{d} \text { Millipore } 0.1 \mu \mathrm{m} \\
\text { Aver. COD inlet } \mathrm{MBBR} 231 \mathrm{mgO} / \ell \\
\text { Aver. SS inlet } \mathrm{MBBR} \sim 68 \mathrm{mgSS} / \ell \\
\text { Aver. SS in membrane reactor } \sim 1200 \mathrm{mgSS} / \ell\end{array}$ & $\begin{array}{l}4 \mathrm{~h} \text { hydraulic retention time (HRT) } \\
\text { Average load: } \\
\text { COD }-12 \mathrm{gO}_{2} / \mathrm{m}^{2} \cdot \mathrm{d} \\
\text { FCOD }-1.2-6.3 \mathrm{gO}_{2} / \mathrm{m}^{2} \cdot \mathrm{d}-\mathrm{GF} / \mathrm{C} 1.2 \mu \mathrm{m} \\
\text { FCOD } 0.45-5.1 \mathrm{gO}_{2} / \mathrm{m}^{2} \cdot \mathrm{d} \text { GF } / \mathrm{C} 0.45 \mu \mathrm{m} \\
\text { FCOD } 0.1-1.6 \mathrm{gO}_{2} / \mathrm{m}^{2} \cdot \mathrm{d}-\text { Millipore } 0.1 \mu \mathrm{m} \\
\text { Aver. COD inlet } \mathrm{MBBR}_{2} 272 \mathrm{mgO} / \ell \\
\text { Aver. SS inlet } \mathrm{MBBR} \sim 83 \mathrm{mgSS} / \ell \\
\text { Aver. SS in membrane reactor } \sim 750 \mathrm{mgSS} / \ell\end{array}$ \\
\hline Membrane reactor & Operating characteristics \\
\hline $\begin{array}{l}\text { Zenon ZW10 membrane pilot module } \\
\text { - Type of membrane }- \text { Hollow fibre } \\
\text { - Nominal pore size }-0.04 \mu \mathrm{m} \\
\text { - Configuration - outside/in } \\
\text { Volume of membrane reactor }-27 \ell\end{array}$ & $\begin{array}{l}\text { Flux - 50 LHM, backwash flux }-80 \mathrm{LHM} \\
\text { Total permeate production }-40.5 \mathrm{l} / \mathrm{h} \\
\text { Concentrate flow }-2 \mathrm{l} / \mathrm{h} \\
\text { Operating cycle: } 9.5 \mathrm{~min} \text {. production } \\
\quad 0.5 \mathrm{~min} \text {. backwashing } \\
\text { Recovery } \sim 96 \%\end{array}$ \\
\hline
\end{tabular}

Figure 1 Schematic of the biofilm-MBR process configuration

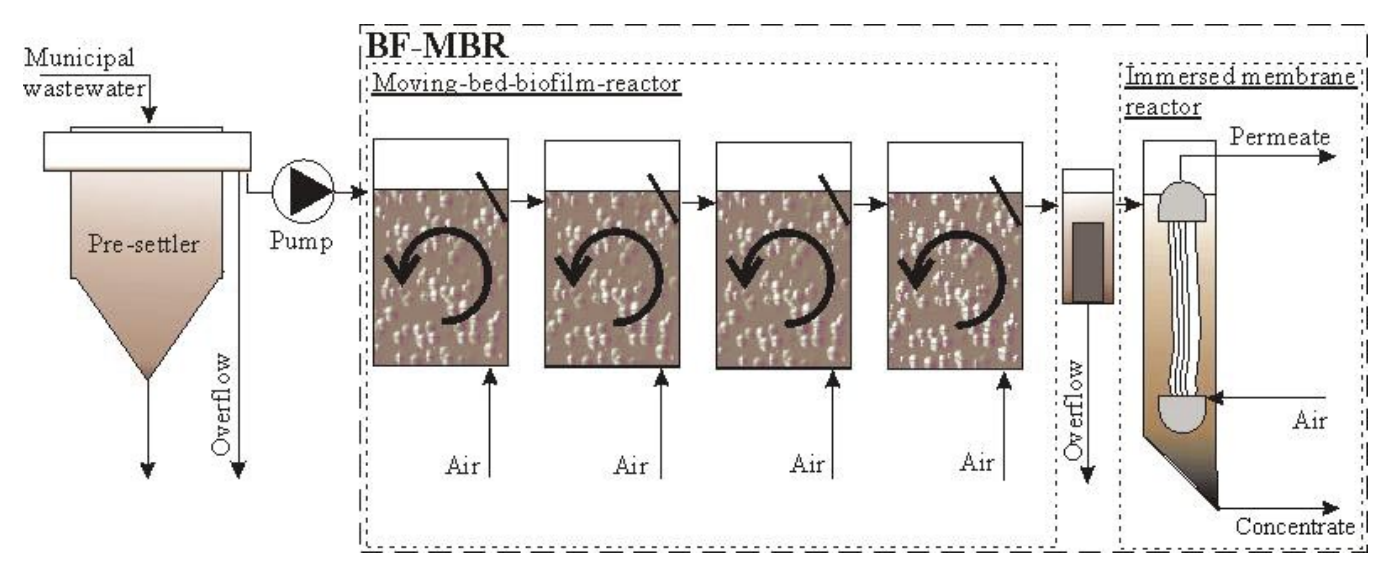

colloidal particles on membrane fouling and the overall performance of the BF-MBR process (combining a moving bed biofilm reactor with a submerged membrane reactor) as a function of varying operating conditions.

\section{Material and methods}

\section{Experimental setup}

A schematic of the process configuration and pilot plant study is shown in Fig. 1. The BF-MBR process consists of the following stages; the moving-bed-biofilm reactor followed by an immersed membrane reactor with module.

The biological treatment process: Four moving-bed-biofilm (MBBR) reactors were installed in series as shown in Fig. 1. The pilot-plant data and operation characteristics of the MBBR are shown in Table 1. To evaluate the effect of different organic loading rates on the overall performance of the process two operating modes defined as high rate and low rate respectively were chosen. The high-rate mode represents organic loading levels where no nitrification occurs while complete nitrification is achieved under the low-rate mode of operation. The hydraulic retention times (HRT) in the biofilm reactor for the two conditions are an HRT of $1 \mathrm{~h}$ for the high rate and an HRT of $4 \mathrm{~h}$ for the low rate respectively. When operating in the high-rate mode, only one of the four MBBRs was used, while all four reactors were used during the low-rate operational conditions.

The membrane separation process: The membrane reactor was based on a submerged reactor design. This configuration allows for a dead-end mode of operation as well as continuous or periodic removal of concentrate. Air scouring can also be applied which generates localised cross-flow conditions along the membrane surface. The localised cross-flow rate is a function of flux and air-flow rate. In this study continuous and periodic extraction of concentrate was employed in combination with continuous air scouring. Details of the pilot plant and operating modes are given in Table 1. A ZW-10 pilot-plant membrane module supplied by Zenon Environmental Inc. was applied in this study. The overall performance of the membrane process and membrane fouling was determined by measuring changes in 


\begin{tabular}{|c|c|c|c|c|c|c|c|c|}
\hline \multicolumn{9}{|c|}{$\begin{array}{l}\text { TABLE } 2 \\
\text { Average treatment efficiencies of the process for the respective stages }\end{array}$} \\
\hline & & \multirow{2}{*}{ Unit } & \multicolumn{3}{|c|}{ High rate } & \multicolumn{3}{|c|}{ Low rate } \\
\hline & & & Aver & Max & Min & Aver & $\operatorname{Max}$ & Min \\
\hline \multirow{5}{*}{ Raw water } & SS & $\mathrm{mg} / \ell$ & 82.4 & 90.8 & 75.3 & 68 & 82 & 55.5 \\
\hline & COD & \multirow{4}{*}{$\mathrm{mgO}_{2} / \ell$} & 272.4 & 312 & 226 & 242.6 & 328 & 201 \\
\hline & FCOD - $1.2 \mu \mathrm{m}$ & & 136.2 & 148.6 & 113.6 & 126.5 & 169 & 80.6 \\
\hline & FCOD $-0.45 \mu \mathrm{m}$ & & 105.8 & 116 & 94.3 & 111.7 & 152 & 75.2 \\
\hline & FCOD - $0.1 \mu \mathrm{m}$ & & 76.4 & 95.3 & 61.7 & 102.9 & 127 & 68.2 \\
\hline \multirow{5}{*}{$\begin{array}{l}\text { MBBR } \\
\text { effluent }\end{array}$} & SS & $\mathrm{mg} / \ell$ & 116.3 & 206.7 & 83.4 & 100 & 201 & 60 \\
\hline & COD & \multirow{4}{*}{$\mathrm{mgO}_{2} / \ell$} & 207.2 & 248.8 & 180.4 & 154.3 & 202 & 117.2 \\
\hline & FCOD - $1.2 \mu \mathrm{m}$ & & 63.3 & 71 & 59 & 37.4 & 49.1 & 27.5 \\
\hline & FCOD - $0.45 \mu \mathrm{m}$ & & 46.1 & 46.8 & 45.5 & 33.2 & 45 & 25.2 \\
\hline & FCOD - $0.1 \mu \mathrm{m}$ & & 34.8 & 38 & 30 & 24.8 & 31.2 & 18 \\
\hline \multirow{5}{*}{$\begin{array}{l}\text { Membrane } \\
\text { reactor }\end{array}$} & SS & $\mathrm{mg} / \ell$ & 1206.3 & 1357.3 & 922.2 & 757 & 1360 & 573 \\
\hline & COD & \multirow{3}{*}{$\mathrm{mgO}_{2} / \ell$} & 1616.7 & 2040 & 1290 & 1106.4 & 1630 & 830 \\
\hline & FCOD - $1.2 \mu \mathrm{m}$ & & 151.9 & 195.2 & 123 & 91.2 & 133 & 77.4 \\
\hline & FCOD - $0.45 \mu \mathrm{m}$ & & 86.5 & 112 & 72.4 & 67 & 76.3 & 59.5 \\
\hline & FCOD - $0.1 \mu \mathrm{m}$ & & 66.3 & 79.8 & 51.4 & 50 & 61.7 & 46.4 \\
\hline \multirow{2}{*}{ Permeate } & $\mathrm{SS}$ & $\mathrm{mg} / \ell$ & 0 & 0 & 0 & 0 & 0 & 0 \\
\hline & FCOD - $0.04 \mu \mathrm{m}$ & $\mathrm{mgO}_{2} / \ell$ & 32.7 & 34.5 & 31.7 & 23.5 & 30.5 & 17.6 \\
\hline \multirow{5}{*}{ Concentrate } & SS & $\mathrm{mg} / \ell$ & 1269.2 & 1646.3 & 869.6 & 1178 & 2361 & 635 \\
\hline & COD & \multirow{4}{*}{$\mathrm{mgO}_{2} / \ell$} & 1656.7 & 2120 & 1320 & 1403.2 & 2140 & 1034 \\
\hline & FCOD - $1.2 \mu \mathrm{m}$ & & 150.2 & 198.2 & 119 & 84.4 & 128 & 74.1 \\
\hline & FCOD $-0.45 \mu \mathrm{m}$ & & 95 & 116 & 82.6 & 69.5 & 94.4 & 66.4 \\
\hline & FCOD $-0.1 \mu \mathrm{m}$ & & 62.5 & 72.2 & 50.8 & 52.8 & 64.1 & 46.9 \\
\hline
\end{tabular}

the trans-membrane pressure (TMP) over time for a constant flux operation. The development of TMP was measured continuously using an online pressure transducer connected to a data acquisition system from National Instruments, FieldPoint (FP1000 with FP-AI-110 analogue input), in combination with the LabVIEW 6.1 data acquisition and analysis program. The water temperature was also logged continuously with a temperature transducer. Water flow rates were monitored and checked once a day.

\section{Analysis}

All analyses were performed according to the Norwegian national or international standards. Suspended solids (SS) were analyzed by filtering through a Whatman $\mathrm{GF} / \mathrm{C} 1.2 \mu \mathrm{m}$ according to the NS 4733. Chemical oxygen demand (COD) was measured with the Dr Lange LCK314 cuvette test. For the filtered chemical oxygen demand (FCOD) samples were first filtered with Whatman GF/C glass micro-fibre filters $(1.2 \mu \mathrm{m}$ and 0.45 $\mu \mathrm{m})$ and with Millipore $0.1 \mu \mathrm{m}$ filters, recorded as FCOD-1.2, FCOD-0.45 and FCOD-0.1 respectively. Samples were filtered successively in order to determine a simplified fractional COD distribution. Capillary suction time-CST (according to Standard Methods, 1998) and time-to-filtrate-TTF (according to a modified method (Standard Methods, 1998) were preformed in order to evaluate dewatering and filtering characteristics of the concentrate. Particle size distribution (PSD) analysis of the water in the various stages of the process was also done using laser diffraction spectroscopy (Beckman Coulter LS230). TMP was logged every $2 \mathrm{~s}$. The data files were filtered by a C++ script in MS Visual Studio 6.0 where values from the beginning of a production cycle were extracted and plotted. Five different sampling points were chosen; raw water inlet, MBBR effluent, membrane reactor (middle zone), permeate and concentrate.

\section{Results and discussion}

\section{Process performance}

A summary of the measured values for SS, COD and the three FCOD fractions for the respective stages and flows of the process for the high and low loading conditions are given in Table 2. Experiments are conducted on wastewater pumped into the research hall from the public sewer and inlet wastewater quality therefore varied as a function of natural diurnal variations and wet/dry weather conditions. From the summary it is apparent that the raw water qualities do not vary too much over the experimental period. MBBR effluent values show a difference in effluent quality where lower COD and FCOD values are achieved under low rate conditions, pointing to better removal of organic matter during the low rate operation. A significant difference is noticed in the SS concentration in the membrane reactor as a function of operating mode, showing that the composition and characteristics of the SS in the MBBR effluent is a function of organic loading rate. COD measured in the permeate represents the inert or non biodegradable COD concentration in inlet wastewater. The permeate concentration of COD is less for low rate operation, and is probably a result of more of the less biodegradable COD being removed during low rate operation which has a higher HRT.

Table 3 summarises the raw water quality and average removal efficiency for low- and high-rate operating modes respectively. Based on permeate quality measurements it is not possible to make distinguishable differences in the overall treatment efficiency for the process with the two operating conditions tested in this study. Although slightly different average COD values in the influent are reported and percentage removals are a little higher for the low rate mode, the permeate qual- 


\begin{tabular}{|c|c|c|c|c|c|}
\hline \multicolumn{6}{|c|}{$\begin{array}{c}\text { TABLE } 3 \\
\text { Summary of raw water quality and average removal efficiency }\end{array}$} \\
\hline \multirow[t]{2}{*}{ Parameter } & \multirow[t]{2}{*}{ Unit } & \multicolumn{2}{|c|}{ Low rate } & \multicolumn{2}{|c|}{ High rate } \\
\hline & & Average & Average removal & Average & Average removal \\
\hline $\mathrm{SS}^{1}$ & $\mathrm{mg} / \ell$ & 68 & $100 \%$ & 82.4 & $100 \%$ \\
\hline COD & \multirow{4}{*}{$\mathrm{mgO}_{2} / \ell$} & 242.6 & $90 \%$ & 272.4 & $88 \%$ \\
\hline FCOD $-1.2^{2}$ & & 126.5 & $70 \%$ & 136.2 & $54 \%$ \\
\hline FCOD $-0.45^{2}$ & & 111.7 & $70 \%$ & 105.8 & $56 \%$ \\
\hline FCOD-0.1 ${ }^{2}$ & & 102.9 & $76 \%$ & 76.4 & $54 \%$ \\
\hline
\end{tabular}

SS is not measured in permeate; nominal pore size of membrane is $0.04 \mu m$ compared to nominal pore size of $G F / C$ filter $1.2 \mu \mathrm{m}$

2 Removal in $M B B R$

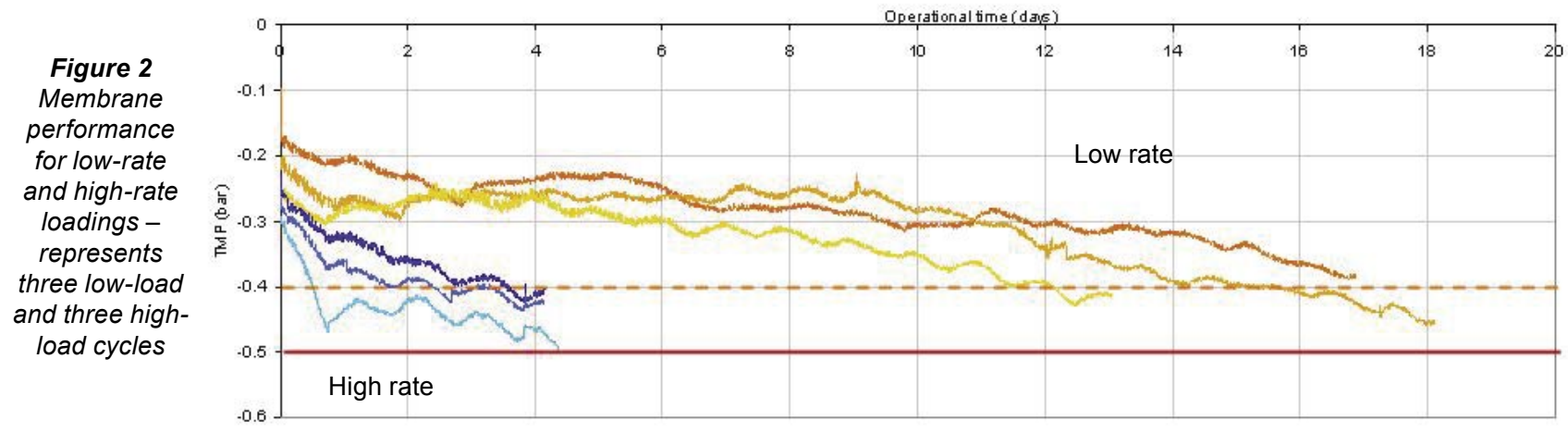

ity shows consistent values irrespective of the operating modes. COD values in the permeate are comparable to previous results obtained and represent the non-biodegradable COD fraction in the wastewater (Leiknes et al., 2005; Âhl et al., 2005; Melin et al., 2005). Slightly higher COD values for the high-rate mode may be due to poorer removal of particulate organic matter due to hydrolysis limitations in the shorter HRT of the reactor. The membrane performance, however, was affected by the different organic loading rates and the effect of this on membrane fouling can be seen.

\section{The membrane performance}

The membrane performance was evaluated by monitoring the development of the TMP over time for the high rate and low rate modes of operating respectively. Increase in TMP with time correlates to a permeability decline rate (i.e. fouling rate) and ultimately determines how long a sustainable operation of the membrane filtration unit can be achieved for a given operating mode (i.e. flux as a function of feed characteristics). When the TMP reaches a set maximum value membrane fouling is so significant that chemical cleaning is necessary to remove irreversible fouling and recover the performance of the membrane. For the membrane unit used in this study a maximum TMP of 0.5 bar was set for initiation of chemical cleaning and the pilot plant was operated until the TMP reached a value between 0.4 to 0.5 bar. Figure 2 shows the TMP development measured for six experiments; three times operated with a high-rate mode and three times with a low-rate mode. The membrane unit was operated in the same way for all experiments with respect to permeation flux, backwashing flux, operation cycles, air scouring rates, recovery, etc. The rate of permeability decline is given by the TMP value measured immediate after a backwash cycle is completed, and represents an overall fouling rate which determines the degree of irreversible fouling as a function of the operating mode. The values shown in Fig. 2 represent the TMP value measured immediately after a backwash.
From Fig. 2 it is apparent that fouling rates measured during the high rate mode are higher compared to the low rate mode for the conditions tested in this study. The consequence is much shorter operational cycles before chemical cleaning is required and consequently a less desirable performance of the membrane filtration unit. The difference in membrane performance can be attributed to different fouling behaviour of the wastewater based on the concentrate characteristics. Fouling mechanisms are complex and interrelated and analysis of the membrane reactor streams was done in an attempt to identify the dominating fouling mechanism. Various measurements and analyses were conducted to correlate the membrane performance to the SS properties, particulate characteristics and the dissolved constituents. The membrane performance was therefore evaluated with regard to measured values of SS, COD/FCOD, and particle size distribution (PSD) analysis. No clear correlation between SS and COD measured and the permeability decline were seen. A relationship between the measured FCOD-1.2 and TMP was found as illustrated in Fig. 3.

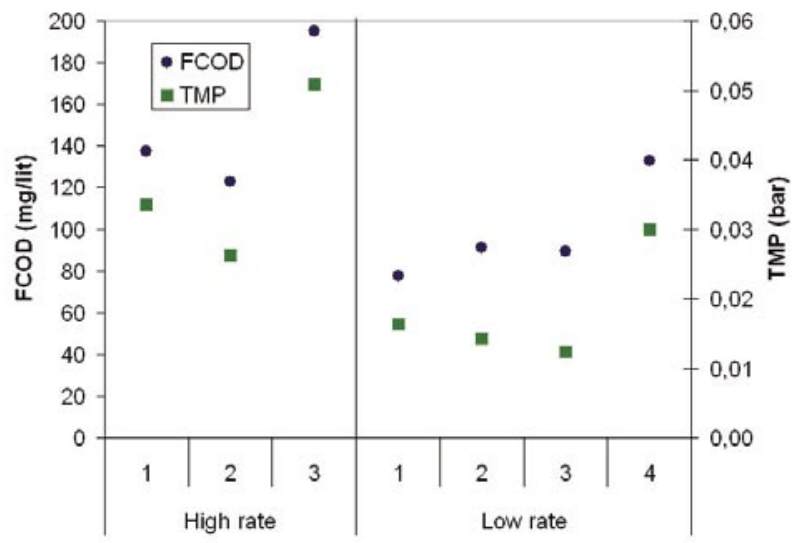

Figure 3

Comparison of total FCOD and TMP 
Retentate Low vs. High

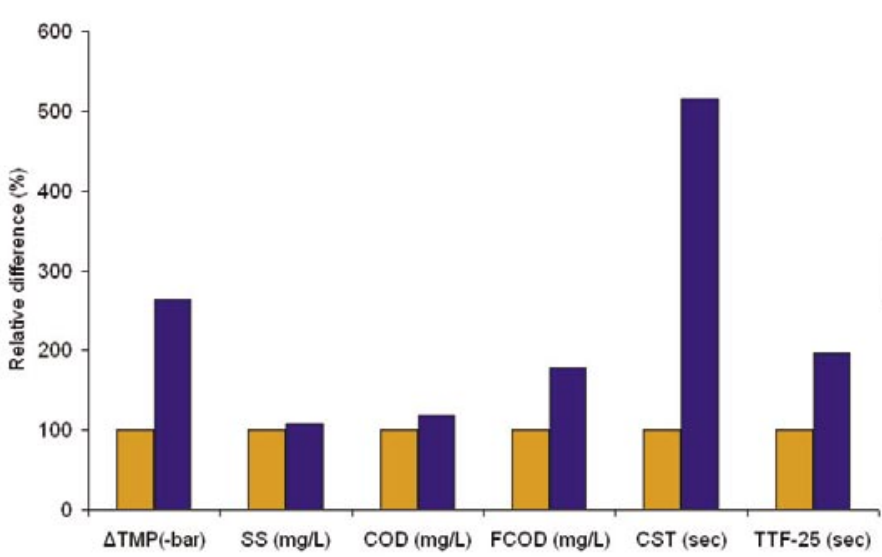

Figure 4

Concentrate characteristics - relative differences $\%$

High vs Low rate - MBBR effluent

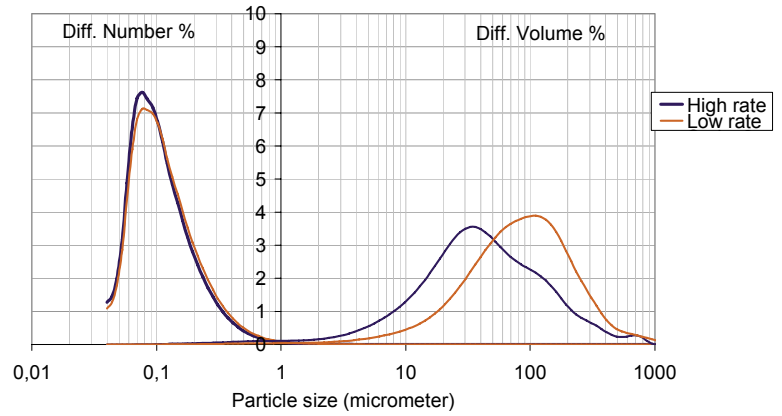

a) PSD in diff. number and volume \% - MBBR

High vs Low rate - Membrane reactor

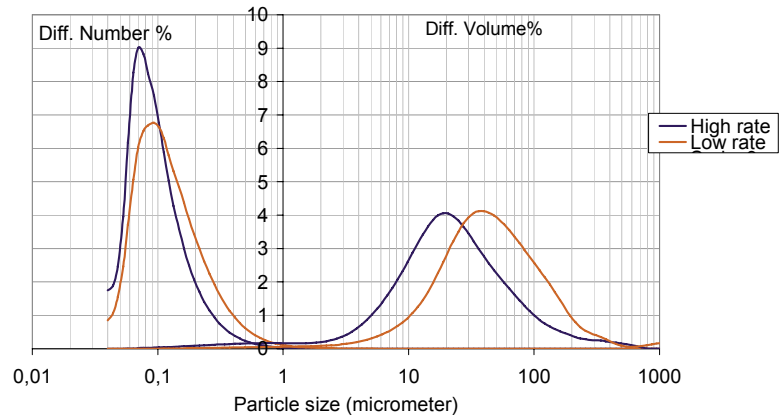

b) PSD in diff. number and volume \% - membrane reactor High vs Low rate - Concentrate

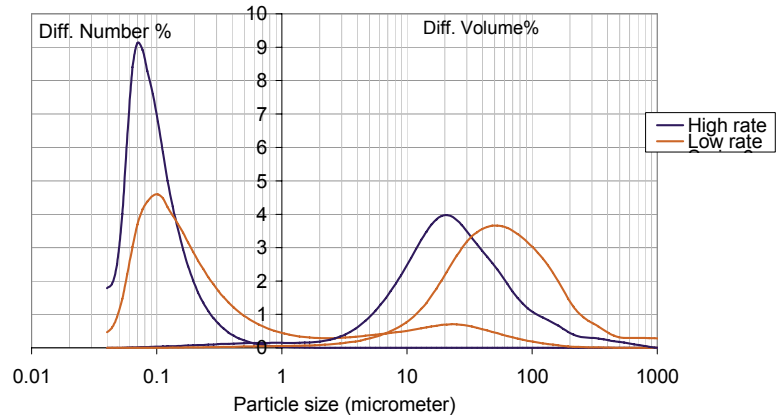

c) PSD in diff. number and volume $\%$ - concentrate

Figure 5

Particle size distributions as a function of loading rates
Recent studies show that still it is not clear under which circumstances, which particles are mainly responsible for the fouling. Some studies reported that SS properties are most important for membrane fouling (Defrance et al., 2000; Bae et al., 2005), while others have identified EPS concentrations as a major factor (Wisniewski et al., 2000; Li et al., 2005), and others have shown that the submicron particles below $0.1 \mu \mathrm{m}$ are a main fouling factor (Cicek et al., 2003; Pollice et al., 2005), while yet others have reported that the colloids and soluble fractions are most often responsible for the fouling effects (Wisniewski et al., 2000; Rosenberger et al., 2006). Figure 3 suggests that in a BF-MBR the fraction of organic matter below $1.2 \mu \mathrm{m}$ is one of the main contributing factors to membrane fouling.

\section{Concentrate characteristics - low vs. high operating mode}

Figure 4 illustrates relative differences in measured concentrate characteristic values for the two operating modes investigated in this study. A capillary suction time analysis (CST) shows a significant difference between the two modes. CST is a measure of the dewatering characteristics of solids/sludge where values below 100s indicate good dewatering characteristics. CST values were commonly below $50 \mathrm{~s}$ for the low-rate mode and mostly higher than $150 \mathrm{~s}$ for the high-rate mode. Results showed that the low rate mode had consistently better dewatering characteristics. Time to filter $25 \%$ of sampled volume (TTF25) represents the filterability of the concentrate. Both measurements indicate that low-rate suspensions had potentially better filtering characteristics and floc structure that appear to be more favourable for membrane filtration. Lower values represent better filtering characteristics which were observed for low-rate concentrate around $27 \mathrm{~s}$ and around $57 \mathrm{~s}$ for high rate. Concentration of FCOD was significantly higher for high-rate concentrates which indicates that colloidal organic fractions could be responsible for poorer concentrate characteristics during the high rate mode of operation. More detailed analyses of the particle size distribution (PSD) were therefore conducted to assess how the membrane performance correlated to this concentrate property.

\section{Effect of the particle size distribution on fouling}

Particle size distribution (PSD) analysis for the water streams was evaluated for the inlet feed water, the MBBR effluent, and the membrane reactor and concentrate respectively. No SS were detected in the permeate and PSD analysis was therefore not performed for the permeate. Figure 5 shows typical PSD distribution for named sampling points expressed in differential number $\%$ and differential volume $\%$. PSD differential volume $\%$ analysis shows that low rate operational conditions produce an effluent from the bioreactor with a higher amount of large particles, mostly around $100 \mu \mathrm{m}$ (Fig. 5a), while for the high rate the most abundant fraction of particles was between 20 and $30 \mu \mathrm{m}$. In membrane reactor this value decreased slightly for both modes of operation (Fig. 5b) and can most probably is due to particle breakage during the aeration. From the data measured it is not possible to make an assessment of the respective particle aggregate strengths. In the concentrate the distribution in volume $\%$ has the same trend for both operational conditions. 
Analyses of the submicron fraction shows no significant differential number \% of particles in the PSD profile for the MBBR effluent for low and high rate operation respectively (Fig. 5a). In the membrane reactor and the concentrate stream, however, the measured values are significantly different for the submicron particles with a diameter of around 0.05 to $0.07 \mu \mathrm{m}$. The number is almost twice as high for the concentrate analysis for the high-rate mode. If this colloidal fraction is a significant contribution and dominant mechanism of the membrane fouling, the results offer a reasonably good explanation for the higher fouling rates observed during the highrate mode of operation. This finding is in agreement with other studies where submicron colloidal fractions are reported as a significant foulant (Leiknes et al., 2005). Furthermore, the differential number \% of submicron particles in the membrane reactor and concentrate are almost the same for high-rate operation. For the low-rate operation a lower value is measured in the concentrate suggesting an aggregation for the submicron particles taking place. This results in a lower amount of these particles around the membrane, i.e. less fouling by colloids during low rate and an overall improved membrane performance observed for low-rate operation. The lower amount of submicron particles in concentrate for low-rate operation is also a contributing factor for better dewatering and filtering characteristics measured for the low-rate concentrate.

\section{Effect of the FCOD distribution on fouling}

A simplified FCOD fraction distribution was also performed in order to determinate which fraction of COD below 1.2 may have a major effect on membrane fouling. Figure 6 summarises results for high- and low-rate operation for three different fractions; below $0.1 \mu \mathrm{m}$, between 0.1 and $0.45 \mu \mathrm{m}$ and 0.45 and 1.2. Analysis was done on the same streams as the PSD analysis.

A higher COD concentration was measured for the 0.45 to $1.2 \mu \mathrm{m}$ fraction in the membrane reactor (i.e. around the membrane) during the high rate operation, while the amount in fraction below $0.1 \mu \mathrm{m}$ was found to be slightly lower. From the PSD analysis it was expected that a higher amount of submicron organic particles around $0.1 \mu \mathrm{m}$ should be found as Fig. 5 b suggests. From Fig. 6 and Fig. 5 b one could postulate that the number of the colloidal fraction below $0.45 \mu \mathrm{m}$ appears to be the most important contributing factor to membrane fouling. However, the COD analysis does not take into account colloidal particles that are not of an organic nature. The analysis does not differentiate between the nature of the organic compounds and as such evaluations as to the effect of EPS/SMP in the samples and their significance to the fouling observed has not been assessed. Additional and more detailed analysis of the colloidal fractionations are necessary to make an full assessment of the impact of this colloidal fractions on membrane fouling and thereby contribute to a better understanding of dominating mechanisms in membrane fouling. Studies are currently being conducted to expand on these issues.

\section{Conclusions}

A BF-MBR process was investigated in terms of membrane fouling, and two different operational modes of the biological filter were investigated. Results from various measurements and analyses show that operating the bioreactor with a low organic loading rate is more favourable for a stable and long-term operation of the membrane filtration unit. For the overall operating conditions tested membrane fouling was found to be more pro-

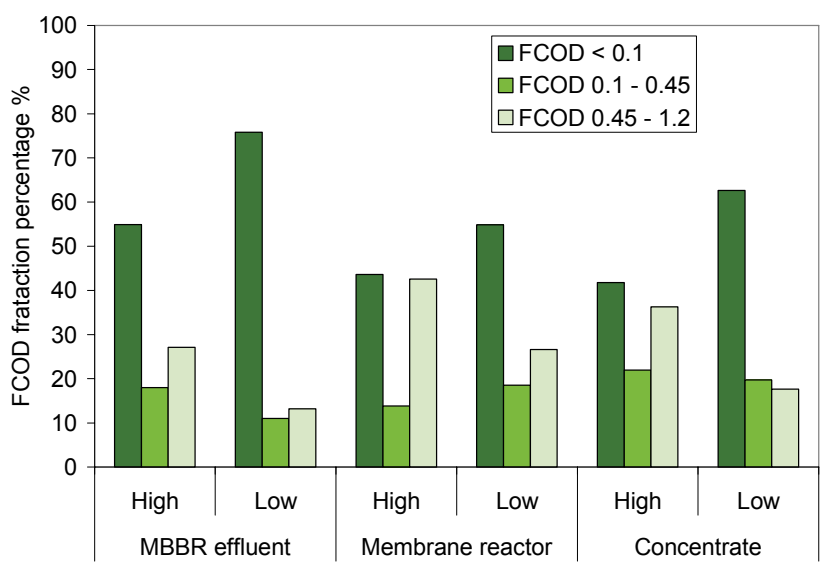

Figure 6

Fractional distribution of FCOD

nounced when a high organic loading rate was applied. Possible reasons are:

- Higher amounts of submicron colloidal particles with diameters of less than $0.45 \mu \mathrm{m}$ were measured around the membrane during the high-rate operation.

- Higher values of the FCOD fraction below $1.2 \mu \mathrm{m}$ in the MBBR effluent were found for high-rate operation. The nature of the organic matter and significance of the fouling observed needs to be further investigated.

- Concentrate analyses indicate more stable and compact floc structures during low-rate operation indicating more favourable filtering conditions with deposition on the membranes exerting less permeation resistance.

- Both PSD analysis and fractional distribution of FCOD indicate that the higher amounts of submicron colloids (below $0.45 \mu \mathrm{m}$ ) in the high-rate mode of operation are a significant contribution and the dominant mechanism of the membrane fouling observed.

The results are in agreement with findings from other studies that identify the significance of the submicron particles on membrane fouling in membrane bioreactor processes (Leiknes et al., 2005). More detailed studies are currently being done to make an assessment of the fouling behaviour of this fraction and the nature of particulate matter. The aim is to determine useful correlations between varying operating conditions and expected fouling potentials based on a selection of analytical measurements.

\section{Acknowledgment}

AnoxKaldnes, Norway, for support with the biofilm reactor and ZENON Environmental Inc., Canada, for supplying the membrane modules.

\section{References}

AIMAR P (2003) Recent progress in understanding particle fouling of filtration membranes. Proc. IMSTEC'03 Conf. 10-14 November 2003, University of New South Wales, Sydney, Australia. (ISBN 0733420893 ).

ÅHL RM, LEIKNES T and ØDEGAARD H (2005) Tracking particle size distributions in a moving bed biofilm membrane reactor for treatment of municipal wastewater. Water Sci. Technol. 53 (7) 33-42.

BAE TH and TAK MT (2005) Interpretation of fouling characteristics of ultrafiltration membranes during the filtration of membrane bioreactor mixed liquor. J. Membrane Sci. 264 (1-2) 151-160. 
CHANG IS, LE CLECH P, JEFFERSON B and JUDD S (2002) Membrane fouling in membrane bioreactors for wastewater treatment. J. Environ. Eng. ASCE 128 (11) 1018-1029.

CICEK N, SUIDAN MT, GINESTET P and AUDIC JM (2003) Impact of soluble organic compounds on permeate flux in an aerobic membrane bioreactor. Environ. Technol. 24 (2) 249-255.

DEFRANCE L, JAFFRIN MY, GUPTA B, PAULLIER $P$ and GEAUGEY V (2000) Contributions of various constituents of activated sludge to membrane bioreactor fouling. Biores. Technol. $\mathbf{7 3}$ $105-112$.

LEIKNES T and ØDEGAARD H (2005) The development of a biofilm membrane bioreactor. Proc. IWA Specialty Conf. on Waste water Reclamation and Reuse for Sustainability (WRRS2005). 7-11 November 2005, Jeju, Korea.

LI M, XIUFEN L,DU G, CHEN J and SHEN Z (2005) Influence of the filtration modes on colloid adsorption on the membrane in submerged membrane bioreactor. Colloids and Surfaces A: Physicochem. Eng. Aspects 264 (1-3) 15 120-125.

MELIN E, LEIKNES T, HELNESS H, RASMUSSEN V and ØDEGAARD H (2005) Effect of organic loading rate on a wastewater treatment process combining moving bed biofilm and membrane reactors. Water Sci. Technol. 51 (6-7) 421-430.

NAGAOKA H, UEDA S and MIYA A (1996) Influence of bacterial extracellular polymers on the membrane separation activated sludge process. Water Sci. Technol. 34 (9) 165-172.
ØDEGAARD H, RUSTEN B, and WESTRUM T (1994) A new moving bed biofilm reactor - Applications and results. Water Sci. Technol. 29 (10-11) 157-165.

ØDEGAARD H, GISVOLD B, HELNESS H, SJØVOLD F and LIAO Z (2000) High rate biological/chemical treatment based on the moving bed biofilm process combined with coagulation. In: $\mathrm{Hahn} \mathrm{HH}$, Hoffmann E and Ødegaard H (eds.) Chemical Water and Wastewater Treatment VI. Springer Verlag, Heidelberg. 245-255.

POLLICE A, BROOKES A, JEFFERSON B, and JUDD S (2005) Subcritical flux fouling in membrane bioreactors - a review of recent literature. Desal. 174 (3) 221-230.

ROSENBERGER S, LAABS C, LESJEAN B, GNIRSS R, AMY G, JEKEL M and SCHROTTER J-C (2006) Impact of colloidal and soluble organic material on membrane performance in membrane bioreactors for municipal wastewater treatment. Water Res. 40710 720.

STANDARD METHODS (1998) Standard Methods For The Examination Of Water And Wastewater (20th edn.) American Public Health Association/American Water Works Association/Water Environment Federation, Washington DC, USA.

WISNIEWSKI C, GRASMICK A and CRUZ A L (2000) Critical particle size in membrane bioreactors - case of a denitrifying bacterial suspension. J. Membrane Sci. 178 141-150. 